\title{
Seatone in rheumatoid arthritis: a six-month placebo-controlled study
}

\author{
J G LARKIN, H A CAPELL, AND R D STURROCK
}

From the Centre for Rheumatic Diseases, 35 Baird Street, Glasgow

SUMMARY Thirty-five patients with rheumatoid arthritis were randomly allocated to either Seatone (green-lipped mussel extract) or placebo in order to assess the former's claimed effectiveness in rheumatoid disease. After six months there was no significant improvement in any laboratory or clinical measurement of disease activity in the Seatone group. The patients on active drug fared no better than those on placebo. These results suggest that Seatone is not effective in rheumatoid arthritis.

Key words: drug therapy, alternative medicine, disease-modifying drugs.

In 1980 Gibson et al. ${ }^{1}$ suggested that the greenlipped mussel extract Perna canaliculus (Seatone) was an effective alternative to the established 'disease-modifying drugs' in rheumatoid arthritis (RA). The preparation was claimed to be as effective as gold injections while having none of the toxicity of the standard second-line therapies. These findings were later disputed, but in a short-term study. ${ }^{2}$ We therefore undertook a placebocontrolled study where every effort was made to maintain patients for six months on the trial drug.

\section{Patients and methods}

The thirty-five patients studied all had definite or classical RA and attended the outpatient department of the Centre for Rheumatic Diseases, Glasgow. All had active disease, not adequately controlled by non-steroidal anti-inflammatory drugs (NSAIDs). Patients were randomly allocated to receive Seatone (20 patients) or placebo (15 patients) on a double-blind basis. The placebo was prepared by the Pharmacy Department of Glasgow Royal Infirmary in order to simulate the characteristic aroma of the green-lipped mussel capsules. No patient had taken the preparation before, and the patients were questioned as to possible fish allergies before entering the study. Patients continued NSAIDs during the trial, and one patient in the

Accepted for publication 6 September 1984.

Correspondence please to $\mathbf{J}$ Larkin, now Registrar in General Medicine, Gartnavel General Hospital, Glasgow. placebo group continued to take $5 \mathrm{mg}$ of prednisolone as she had done for many years. No patient had been on any other second-line therapy in the previous three months.

The dosage of Seatone was one $230 \mathrm{mg}$ capsule four times daily for three months increasing to five times daily for a further three months. Placebo was given in the same pattern.

Disease activity was assessed at 0,3 , and 6 months by both clinical-Ritchie index ${ }^{3}(\mathrm{RI})$, grip strength ${ }^{4}$ (GS), morning stiffness or limbering-up time (LUT), and visual analogue scales $^{5}$ (VAS)-and laboratory parameters (ESR, haemoglobin, platelets, globulins, immunoglobulins, and rheumatoid factor). A biochemical screen for any possible side effects was also carried out at 0 and 6 months.

Visual analogue scales were marked on a $10 \mathrm{~cm}$ line with patients responding to the questions: (1) How bad is your pain at the present moment (VAS 1)? (2) How bad is your pain first thing in the morning (VAS 2)? (3) How bad is your 'arthritis' in general (VAS 3)?

Non-parametric statistics were performed to compare 0 and 6 month parameters of those patients who finished the course of each drug (Wilcoxon rank) and to compare this performance over the six months for the Seatone group versus the placebo group (Mann-Whitney).

\section{Results}

The characteristics of the Seatone and placebo groups on entering the study are shown in Table 1. 
Table 1 Patient characteristics at start of study

\begin{tabular}{lll}
\hline & $\begin{array}{l}\text { Seatone } \\
\text { median (range) }\end{array}$ & $\begin{array}{l}\text { Placebo } \\
\text { median (range) }\end{array}$ \\
\hline Age (years) & $60(54-77)$ & $60(48-70)$ \\
Duration (years) & $12(2-40)$ & $7(1-25)$ \\
ESR (mm/1st h) & $46(6-87)$ & $49(14-91)$ \\
Haemoglobin (g/dl) & $13 \cdot 0(7 \cdot 0-16 \cdot 7)$ & $12 \cdot 2(9 \cdot 3-15 \cdot 1)$ \\
Platelets (× 10'/) & $348(153-549)$ & $308(246-770)$ \\
RF (Rose-Waaler) & $1 / 32($ neg-1/1028) & $1 / 64($ neg-1/512) \\
IgG (g/l) & $13 \cdot 6(7 \cdot 4-21 \cdot 8)$ & $12 \cdot 9(9 \cdot 2-18 \cdot 4)$ \\
Ritchie index & $15(4-30)$ & $21(2-30)$ \\
Grip strength (mmHg) & $114(56-284)$ & $86(46-212)$ \\
LUT (min) & $90(0-360)$ & $35(0-120)$ \\
VAS 1 & $4(1-10)$ & $4(1-10)$ \\
VAS 2 & $7 \cdot 5(2-10)$ & $5 \cdot 5(2-10)$ \\
VAS 3 & $6(1-9)$ & $5(2-10)$ \\
\hline
\end{tabular}

There are no significant differences between the groups.

There are no significant differences between the groups. The patients' own appraisal of the effectiveness of the therapy is shown along with the reasons for drop-out in Table 2. Thirteen of the 20 patients on Seatone completed six months, while 12 of the 15 on placebo finished the trial. The median results of those patients who finished the course are shown in Table 3 for 0 and 6 months. None of the parameters showed a significant change between 0 and 6 months on either therapy, while comparisons between the Seatone and placebo groups showed not significant difference, although the better perform $?$ ance of the placebo group with regard to grip strength almost reached significance $(p=0 \cdot 06)$. $\operatorname{Re} \frac{\overline{\bar{D}}}{\bar{D}}$ sults at three months were similar.

The only finding that did reach statistical signifi $\mathbb{\mathscr { }}$ cance was the number of patients who felt theif arthritis was worse on Seatone (6) versus the number feeling worse on placebo (0): $\mathrm{p}<0.05$, Cox's. logistic empirical transform. ${ }^{6}$

No significant changes were noted in the bio chemical screen at six months.

\section{Discussion}

Since all of the established disease modifying drug£ in RA have toxicity as their main drawback, the way? is open for a relatively non-toxic agent with these properties to make a great impact on rheumatologiz cal management. A 'natural' product such as Sea tone has great appeal, particularly for the followers of 'alternative medicine'.

The first attempted controlled trial of Pernos canaliculus was in 1980 (Glasgow Homoeopathic Hospital $^{1}$ ). Twenty-eight patients with RA hade improvements in many of the parameters measured

Table 2 Fate of those entering trial, with patients' own assessment of improvement

\begin{tabular}{llllll}
\hline & Started & Finished & Improved & Same & Worse \\
\hline Seatone & 20 & $13^{*}$ & 4 & 6 & 3 \\
Placebo & 15 & $12 \dagger$ & 5 & 7 & 0 \\
\hline
\end{tabular}

* Seven drop-outs: three gastrointestinal side-effects; two much worse at 3 months, commenced other second-line therapy; one admitted to wards with exacerbation-septic arthritis; one left the area-lost to follow-up.

$\dagger$ Three drop-outs: one gastrointestinal upset; two lost to follow-up.

Table 3 Clinical parameters (medians) at 0 and 6 months in patients who finished course

\begin{tabular}{|c|c|c|c|c|}
\hline & \multicolumn{2}{|c|}{ Seatone } & \multicolumn{2}{|c|}{ Placebo } \\
\hline & 0 & 6 & 0 & 6 (months) \\
\hline $\operatorname{ESR}(\mathrm{mm} / 1 \mathrm{st} \mathrm{h})$ & 41 & 42 & 43 & 50 \\
\hline Haemoglobin (g/dl) & $13 \cdot 0$ & $11 \cdot 9$ & $11 \cdot 7$ & $12 \cdot 0$ \\
\hline Platelets $\left(\times 10^{8} / 1\right)$ & 340 & 374 & 291 & 312 \\
\hline RF & $1 / 16$ & $1 / 32$ & $1 / 16$ & $1 / 64$ \\
\hline $\operatorname{IgG}(g / 1)$ & $13 \cdot 6$ & $14 \cdot 1$ & $12 \cdot 3$ & $10 \cdot 6$ \\
\hline Ritchie index & 15 & 16 & 20 & 13 \\
\hline Grip strength $(\mathrm{mmHg})$ & 129 & 74 & 81 & 92 \\
\hline LUT (min) & 60 & 70 & 45 & 15 \\
\hline VAS 1 & 5 & 4 & 4 & 2 \\
\hline VAS 2 & 8 & 6 & 6 & $5 \cdot 5$ \\
\hline VAS 3 & 6 & 8 & 5 & $3 \cdot 5$ \\
\hline
\end{tabular}

No significant difference between 0 and 6 months.

No significant difference between Seatone and placebo. 
in our own study. However, some statistically significant findings were explained by the authors' manoeuvre of dividing patients into 'responders' and 'non-responders' before analysing the former group for improvement. There was no analysis of active preparation versus placebo. Further letters from the group ${ }^{7}$ rectified some of these problems and maintained that articular index and 'functional index' fared better on the active drug. A later paper showing no benefit from Seatone ${ }^{2}$ was criticised by the original authors because its cross-over procedure and short duration (one month) were incompatible with demonstrating the long-term benefit of Seatone. Another recent study has shown a lack of anti-inflammatory effect from Seatone as shown by analysis of drop-out rates. ${ }^{9}$

Our patients were given a full trial of the preparation. More 'responded' to the placebo than to the 'active' Seatone. In the Seatone group more of the clinical and laboratory parameters deteriorated over the six months than improved, while the drop-out rate was higher than with placebo.

The high response rate in the 1980 trial remains unexplained.

\section{CONCLUSION}

These results do not suggest that Seatone produces any subjective or objective improvement in patients with RA when given over an adequate period. It is an expensive preparation, sold over the counter to patients desperate for improvement. No evidence has been found for it to be marketed as a useful drug in rheumatoid arthritis.

We thank Dorothy Mason, Pharmacy Department, Glasgow Royal Infirmary, for preparation and coding of placebo.

\section{References}

1 Gibson R G, Gibson S L M, Conway V, Chappell D. Perna canaliculus in the treatment of arthritis. Practitioner 1980; 224: 955-60.

2 Huskisson E C, Scott J, Bryans R. Seatone is ineffective in rheumatoid arthritis. $\mathrm{Br}$ Med $J$ 1981; 282: 1358-9.

3 Ritchie D M, Boyle J A, McInnes J M, et al. Clinical studies with an articular index for assessment of joint tenderness in patients with rheumatoid arthritis. $Q J$ Med 1968; 147: 393-406.

4 Lee P, Baxter A, Dick W C, et al. An assessment of grip strength measurement in rheumatoid arthritis. Scand $J$ Rheumatol 1974; 3: 17-23.

5 Huskisson E C. Measurement of pain. Lancet 1974; ii: 1127-31.

6 Cox D R. Analysis of binary data. London: Chapman-Hall, 1971.

7 Gibson R G, Gibson S L M. Green-lipped mussel extract in arthritis. Lancet 1981; i: 439.

8 Gibson R G, Gibson S L M. Seatone in arthritis. Br Med J 1981; 283: 1472 .

9 Caughey D E, Grigor R R, Caughey E B, Young P, Gow P J, Stewart A W. Perna canaliculus in the treatment of rheumatoid arthritis. Eur J Rheumatol Inflamm 1983; 6: 197-200. 